\title{
BACIA HIDROGRÁFICA DO RIO PARAIBUNA: O ZONEAMENTO DO USO E COBERTURA DA TERRA POR IMAGENS DE SATÉLITE COMO SUBSÍDIO PARA O PLANEJAMENTO E A GESTÃO DE RECURSOS
}

\section{Ana Camila da Silva ${ }^{1}$}

\section{Ricardo Tavarez Zaidan ${ }^{2}$}

RESUMO: Este trabalho tem como tema "O Uso e Cobertura da Terra" da Bacia Hidrográfica do Rio Paraibuna que está inserida na Zona da Mata Mineira estendendo-se a uma porção do Estado do Rio de Janeiro, Sudeste do Brasil. Tem como rio principal o rio Paraibuna, e sua pertinência histórica em ser pioneiro nos processos de ocupação da região, possuir grande área de contribuição, aproximadamente $8.597 \mathrm{~km}^{2}$, além de ser o principal receptor dos efluentes de Juiz de Fora, maior cidade da região são as justificativas para escolha dessa área como objeto de estudo. Em revisão bibliográfica consegue-se acompanhar as etapas do uso e ocupação da Bacia e as atividades econômicas que se desenvolveram na área. Através de técnicas de Sensoriamento Remoto (SERE) e análises em Imagens de satélite Landsat - 5, temos como principal objetivo gerar um mapa atual do Uso e Cobertura da Terra da Bacia do Rio Paraibuna que permita o conhecimento, a distribuição e quantificação dos elementos naturais que compõem atualmente a área assim como a tendência de Uso reflete na configuração da cobertura da terra atualmente. O uso de técnicas de SERE permitiu ampliar a escala de análise gerando dados mais precisos quanto à proporção dos elementos em relação à área de drenagem. Visamos com os resultados deste trabalho, subsidiar trabalhos futuros

\footnotetext{
${ }^{1}$ Bacharel em Geografia - ICH/UFJF - acamila.inhan@hotmail.com

2 Professor Dr. Adjunto - DEGEO/ICH/UFJF - ricardo.zaidan@ufjf.edu.br
} 
capazes de atender a necessidades governamentais e auxiliar medidas de planejamento, controle, recuperação, preservação e conservação ao longo da área de estudo.

Palavras-chave: Bacia Hidrográfica, Uso e Cobertura da Terra, Sensoriamento Remoto.

\section{INTRODUÇÃO}

Ao longo da história, as mudanças dos ecossistemas terrestres sempre ocorreram sob diversos níveis de abrangência e razões. Para Drew (1986), com o passar do tempo, a exploração irracional dos recursos naturais e as desordenadas formas de uso e ocupação têm provocado alterações significativas na cobertura dos terrenos, gerando grandes crises ecológicas.

Nesse contexto, um tema que tem sido amplamente discutido é o que se refere à cobertura e uso da terra, devido sua importante atribuição nos trabalhos de planejamento e gestão de recursos. Para Vieira (2005, p. 3) a aplicação desses estudos age como "[...] meio auxiliar nos processos de investigação das causas e conseqüências do crescimento econômico, bem como no monitoramento das constantes alterações dos sistemas globais.". Muitas áreas naturais que antes eram contínuas, hoje se apresentam fragmentadas alterando a estrutura da paisagem e resultando em mudanças na composição e diversidade das comunidades. A Mata Atlântica, bioma no qual a bacia do Rio Paraibuna se encontra e antigamente se configurava de forma contínua, hoje se apresenta fragmentada.

A bacia hidrográfica do Rio Paraibuna foi escolhida primeiramente por ser a bacia hidrográfica, uma unidade fundamental para o planejamento e gestão dos recursos necessários ao desenvolvimento humano, e segundo pelo vale do Rio Paraibuna ter sido historicamente palco dos processos de ocupação, integração regional e afluxo de mercadorias, promovendo o desenvolvimento de vilas e cidades. Sendo assim, as relações entre homem e natureza nesta unidade de território merecem ser estudas, por 
apresentarem características variadas e possuir um importante papel na evolução do terreno.

Desta forma, este trabalho tem como objetivo gerar um mapa atual do Uso e Cobertura da Terra da Bacia do Rio Paraibuna através de processamento de imagens de satélite LANDSAT - 5 do mês de setembro do ano de 2008, permitindo conhecer a distribuição dos elementos geográficos ao longo da área de estudo, contextualizando a região e o perfil do Uso da Terra quanto aos processos sócio-econômicos ao longo do processo histórico de ocupação da Bacia. Os resultados baseiam-se nos dados quantitativos extraídos do método de Classificação Supervisionada aplicados através do software Envi sob licença temporária (outubro/novembro 2009), permitam fazer algumas considerações a respeito da relevância que os elementos naturais e antrópicos têm, se comparados sua dimensionalidade, com a área da bacia. Visamos subsidiar trabalhos futuros relacionados à gestão de recursos e planejamento com os resultados alcançados.

\section{DESENVOLVIMENTO}

\subsection{DESCRIÇÃO E CONTEXTUALIZAÇÃO DA ÁREA DE ESTUDO}

A Bacia do Rio Paraibuna foi escolhida neste trabalho por possuir grande diversidade de cobertura e uso da terra. Possui expressiva área de contribuição, cerca de $8.597 \mathrm{~km}^{2}$ e os limites se encontram fixados nos estados de Minas Gerais e Rio de Janeiro. É ainda, uma das principais sub-bacias da bacia do Paraíba do Sul e compreende uma importante porção industrializada do país. Quanto a sua localização, insere-se na Zona da Mata Mineira, a sul-sudeste do estado de Minas Gerais se estendendo a uma porção do Estado do Rio de Janeiro, Sudeste do Brasil (Fig. 1). Tem como rio principal o Paraibuna, com sua nascente na Serra da Mantiqueira, a cerca de 1180 metros de altitude. Este tem grande importância por ser o principal receptor dos efluentes de Juiz de Fora, maior cidade da bacia. Percorre aproximadamente $166 \mathrm{~km}$, dos quais $44 \mathrm{~km}$ até desaguar na margem esquerda do Rio Paraíba do Sul a 250 metros de altitude, com uma vazão média de aproximadamente $200 \mathrm{~m}^{3} / \mathrm{s}$. Seus principais afluentes são o Rio Preto, o Rio do Peixe e o Rio Cágado (FEAM, 1996). 


\section{LGA \\ BACIA HIDROGRÁFICA DO RIO PARAIBUNA - MG/RJ}
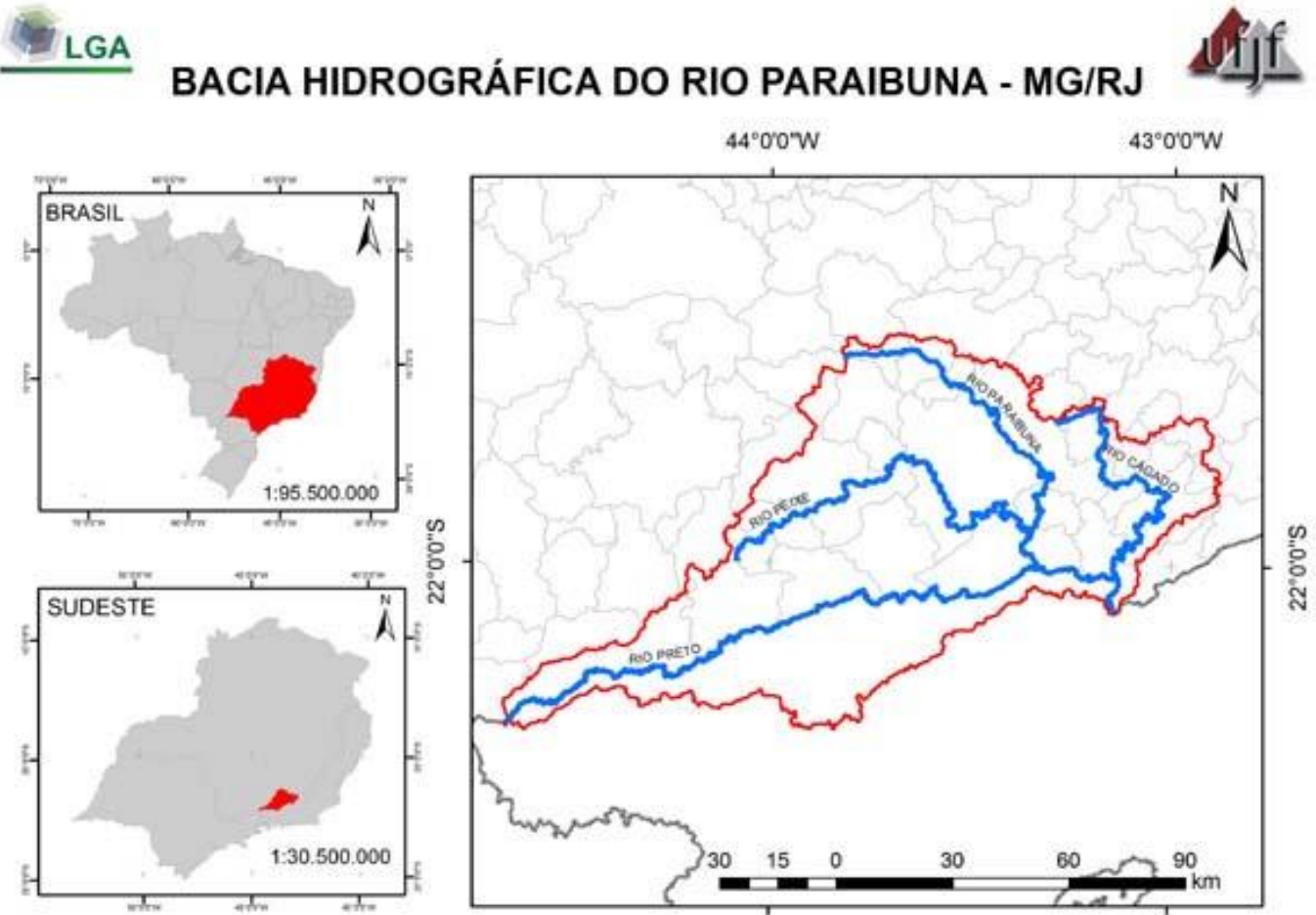

Legenda

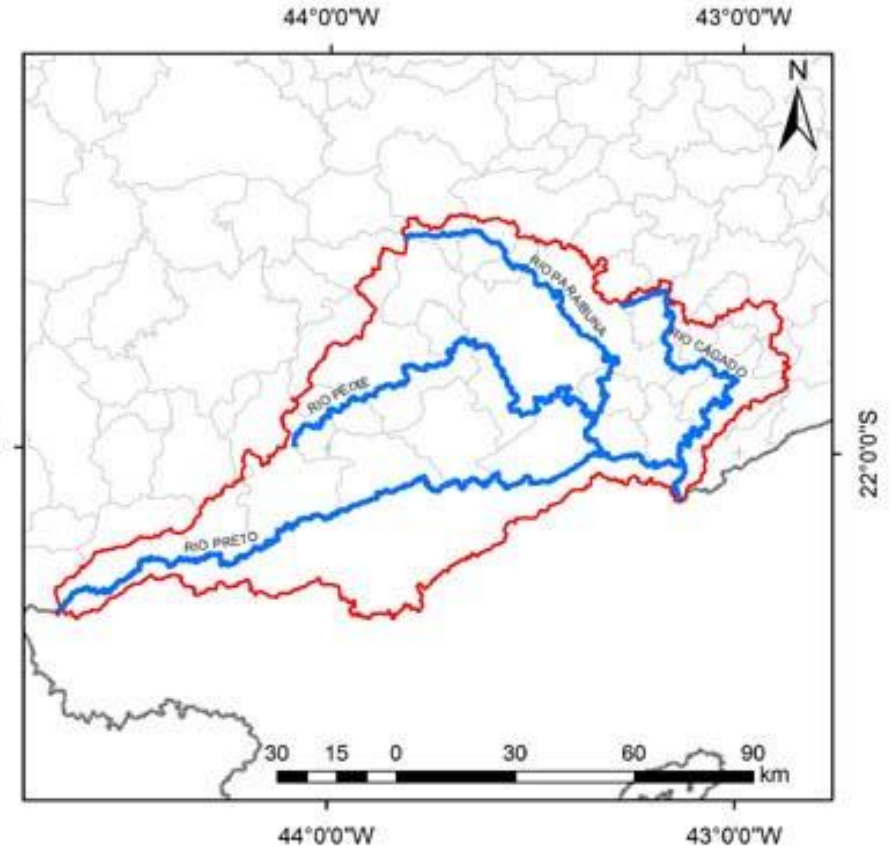

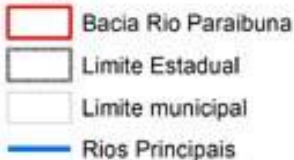

FONTE: BASES DE DADOS IBGELGA

ORGAOO: LGADEGEONJJJF

EXECUTOR ANA CAMILADASUYA

DATA MAIO 2010

Figura 1: Mapa de localização da Bacia Hidrográfica do Rio Paraibuna.

A ocupação e produção do espaço da região da Zona da Mata Mineira e conseqüentemente, da Bacia do Rio Paraibuna, está diretamente ligada aos acontecimentos mundiais, nacionais e regionais desde o período da colonização, vinculada à chegada dos europeus. No século XVIII, com a construção do Caminho Novo (1701-03), a Mata mineira era inicialmente zona de passagem das tropas que se dirigiam da região mineradora - carregadas de ouro - para o porto do Rio de Janeiro e, inversamente, todo tipo de artigos e escravos eram levados para abastecer a região das minas. A produção do espaço da Zona da Mata e da Bacia do Rio Paraibuna tinha como motor as relações econômicas que se davam entre a colônia brasileira e o império português. 
A partir de 1750 a mineração entra em declínio e na terceira década do séc. XIX, a lavoura cafeeira passou a configurar a principal atividade econômica na região. As paisagens das lavouras de café, que embora numerosas, ocupavam áreas relativamente pequenas. As matas estavam localizadas nas encostas mais altas, nas encostas inferiores se cultivava o café e nos vales encontravam-se as sedes da fazenda e as estradas. Estabelecia-se a paisagem humanizada (Valverde, 1958).

Com a diminuição gradativa da cultura cafeeira, a paisagem se modifica e a pecuária passa, aos poucos, tomar o lugar do café, se sobrepondo a este. Assim, tanto a Zona da Mata Mineira como as terras fluminenses contíguas como sugere Valverde, (1958), passam a ter em campo o domínio da pecuária extensiva voltada para a produção leiteira. Giovanini e Matos (2004) afirmam que no caso da Mata, as áreas abandonadas pela cafeicultura foram reaproveitadas para pastagens e cultivos de subsistência. Esta atividade mantém sua influência até nos dias de hoje com a produção de produtos de referência, consumidos regionalmente e na cidade do Rio de Janeiro.

\subsection{METODOLOGIA}

A metodologia utilizada na escolha das classes de uso e cobertura da terra baseia-se no "Sistema de Classificação de Uso da Terra/Cobertura da Terra" do USGS (United States Geological Survey), (Anderson ET AL., USGS, 1992), que "foi especialmente concebido para ser "orientado a recursos" (cobertura da terra), em oposição a vários outros sistemas que são orientados 'a pessoas ou a atividades' (uso da terra)" (JENSEN, 2009). A lógica do USGS baseia-se na necessidade de classificar o uso da terra orientado a recursos, cuja ênfase estaria nas áreas não urbanas e sua aplicabilididade neste trabalho justifica-se pela área de estudo possuir grande diversidade de cobertura e uso da terra. Sendo assim, a área da bacia do Rio Paraibuna foi classificada de acordo com o seguinte nível de classificação: 
- Solo Urbano ou Construído - Elementos: Residencial; Comercial e Serviços; Industrial; Transporte, comunicação e Infra-estrutura; Complexos industriais ou comerciais; Uso urbano e construído Misto; Outros Usos Urbanos.

- Terra Agrícola- Elementos: Lavoura, Pomares, Vinículas, Horticulturas, Outros usos agrícolas. (Esta classe é composta por vegetação plantada, introduzida ou adaptada, destinada às plantações de culturas permanentes e temporárias. Incluem-se áreas com plantas forrageiras destinadas ao corte, terras em descanso e terras produtivas não utilizadas.)

- Pastagem- Elementos: Pasto de gramíneas, Pasto de Arbustos - Capoeira, Pasto misto. (As áreas representadas nesta classe são formadas principalmente por espécies agrostológicas (plantas forrageiras), destinadas ao pastoreio.)

- Florestas- Elementos: Florestas Decíduas, Perenes, Mistas. (Esta classe reúne a maioria dos biomas brasileiros, não sendo distinguidos e pode ser exemplificado com a denominação "área de florestas" que, independente do bioma, considera qualquer tipo de floresta. terem sido derrubadas ou alteradas pela ação do homem ou por fenômenos naturais.)

- Corpos D’Água- Elementos: Rios e canais, lagos, reservatórios.

- Terra Estéril ou Solo Exposto- Elementos: Áreas arenosas (além de praias); afloramento rochoso; Minas a Céu Aberto, Pedreiras; áreas com solo exposto.

\subsection{PROCESSAMENTO DE DADOS}

As técnicas e metodologias de processamento dos produtos aliadas aos sistemas de informação geográfica permitem identificar as intervenções na área de estudo e estabelecer estratégias para uma melhor gestão dos recursos naturais (VIEIRA et al., 2005).

Fonseca (2000) explica que existem dois grupos de classificadores automáticos, baseados no pixel como unidade de classificação: classificador não supervisionado, e classificador supervisionado (utilizado neste trabalho) em que o especialista seleciona 
amostras das classes nas quais a imagem vai ser dividida, que normalmente são descritas por parâmetros estatísticos estimados pelas amostras de treinamento. Os classificadores orientados a objetos também compõem outro grupo classificador e tem sido utilizado atualmente por ser uma excelente solução para classificação em imagens de alta resolução espacial. Estas imagens ainda não se encontram disponíveis gratuitamente, motivo pelo qual inviabilizou a utilização desta técnica neste trabalho.

Para atingir a área da Bacia do Rio Paraibuna foram necessárias a utilização de três imagens digitais datadas do mês 09 de 2008, correspondendo as órbitas 217 (cenas 75 e 76) e 218 (cena 75) cedidas gratuitamente pelo site do Instituto Nacional de Pesquisas Espaciais (INPE), provenientes do satélite LANDSAT 5 que compõe o Programa Espacial " Earth Resources Technology Satellite" lançado pela NASA. A área imageada pelo Landsat é uma faixa de $185 \mathrm{~km}$, recortada em cenas de $185 \mathrm{~km}$ x $185 \mathrm{~km}$ e pixel de $30 \mathrm{~m}$ o que nos permitiu trabalhar numa escala de 1:250.000.

Utilizou-se o processo de fusão entre estas três (03) imagens consecutivas, denominado mosaicagem. As imagens utilizadas datam do mês de setembro de 2008 porque, dentre as mais atuais, foram as únicas que apresentaram pouco ou quase nenhuma presença de nuvens, verificando-se maior qualidade para interpretação e classificação dos elementos na área de estudo.

Após a etapa de mosaico de imagens, foram utilizadas bases vetoriais referentes à drenagem da Bacia do Rio Paraibuna, fornecida pelo IBGE, para o registro da imagem. No processo de georreferenciamento, o vetor da rede de drenagem foi carregado sobrepondo-se à imagem de satélite para facilitar a visualização de pontos estratégicos para a correção (como o encontro de rios, meandros, etc.). Posterior a correção, utilizamos o vetor do limite da bacia para o recorte da área facilitando na coleta de amostras dos elementos (assinatura de classes).

Para facilitar a extração de informações qualitativas da cena em questão foram elaboradas composições coloridas com as imagens das bandas R (TM5) G (TM4), B (TM3), adotando os filtros vermelho, verde, e azul respectivamente. Esta composição de bandas foi escolhida por facilitar a interpretação dos dosséis vegetais, classe de maior representatividade na bacia. A coloração no tom de vermelho, por exemplo, representa as diferentes concentrações/atividades de pigmentos fotossintetizantes na região do visível 
$(0,4-0,72 \mu \mathrm{m})$ e do infravermelho próximo $(0,72-1,10 \mu \mathrm{m})$ explicando diferentes densidades de vegetação.

Para melhor reconhecimento dos elementos contidos na área de estudo, utilizamos apenas o perímetro do município de Juiz de Fora, por ser o maior centro urbano, (Fig.02) para representação dos elementos.

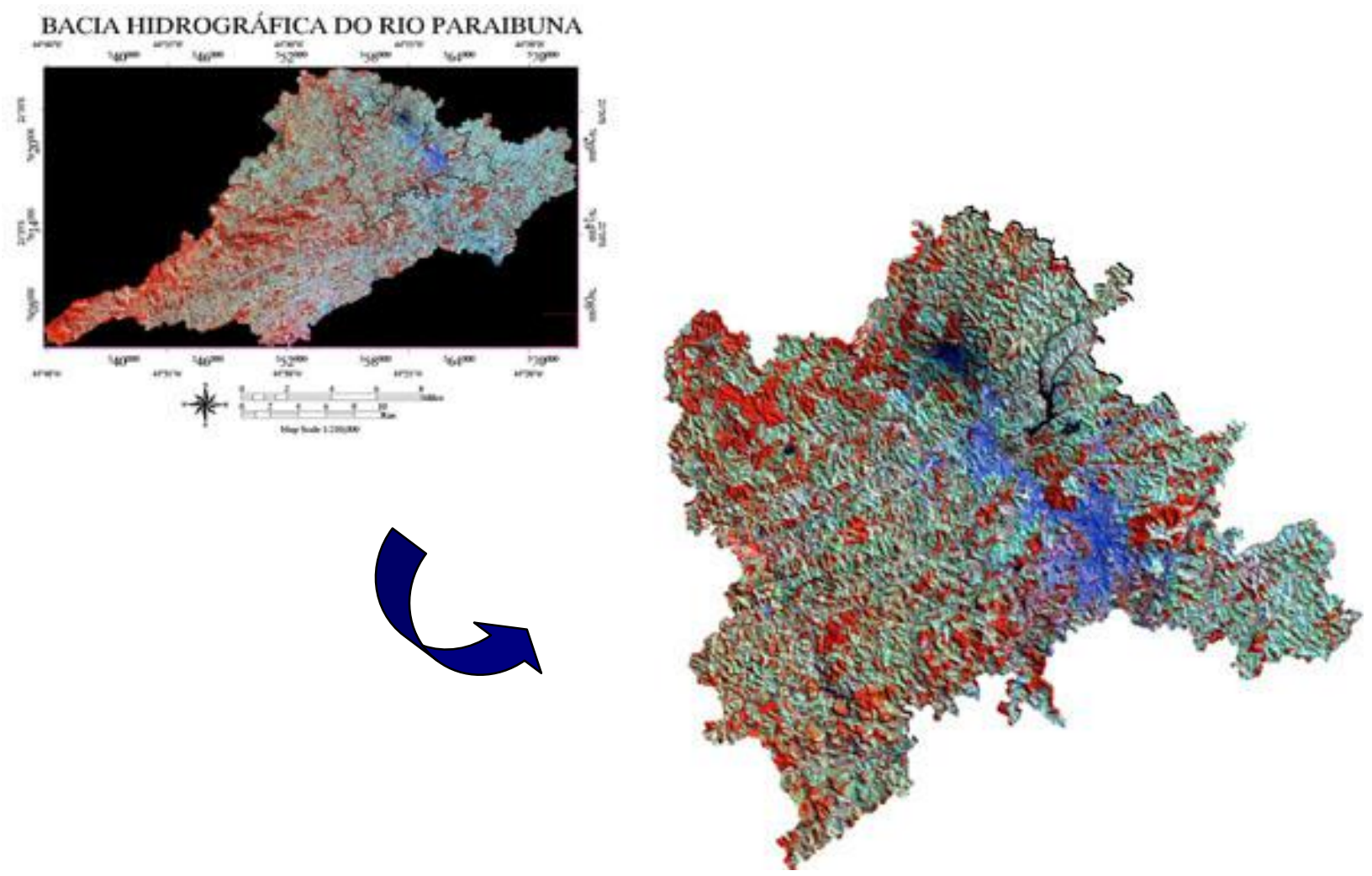

Figura 02: Recorte do perímetro do Município de Juiz de Fora, composição de bandas R (TM4) G (TM5) B (TM3). Fonte: Imagem LANDSAT - 5

Podemos observar nas imagens abaixo (Figura 3 à Figura 10) que a composição de bandas utilizada no trabalho foi capaz de discernir as classes de forma eficaz validando os resultados a serem apresentados posteriormente. 

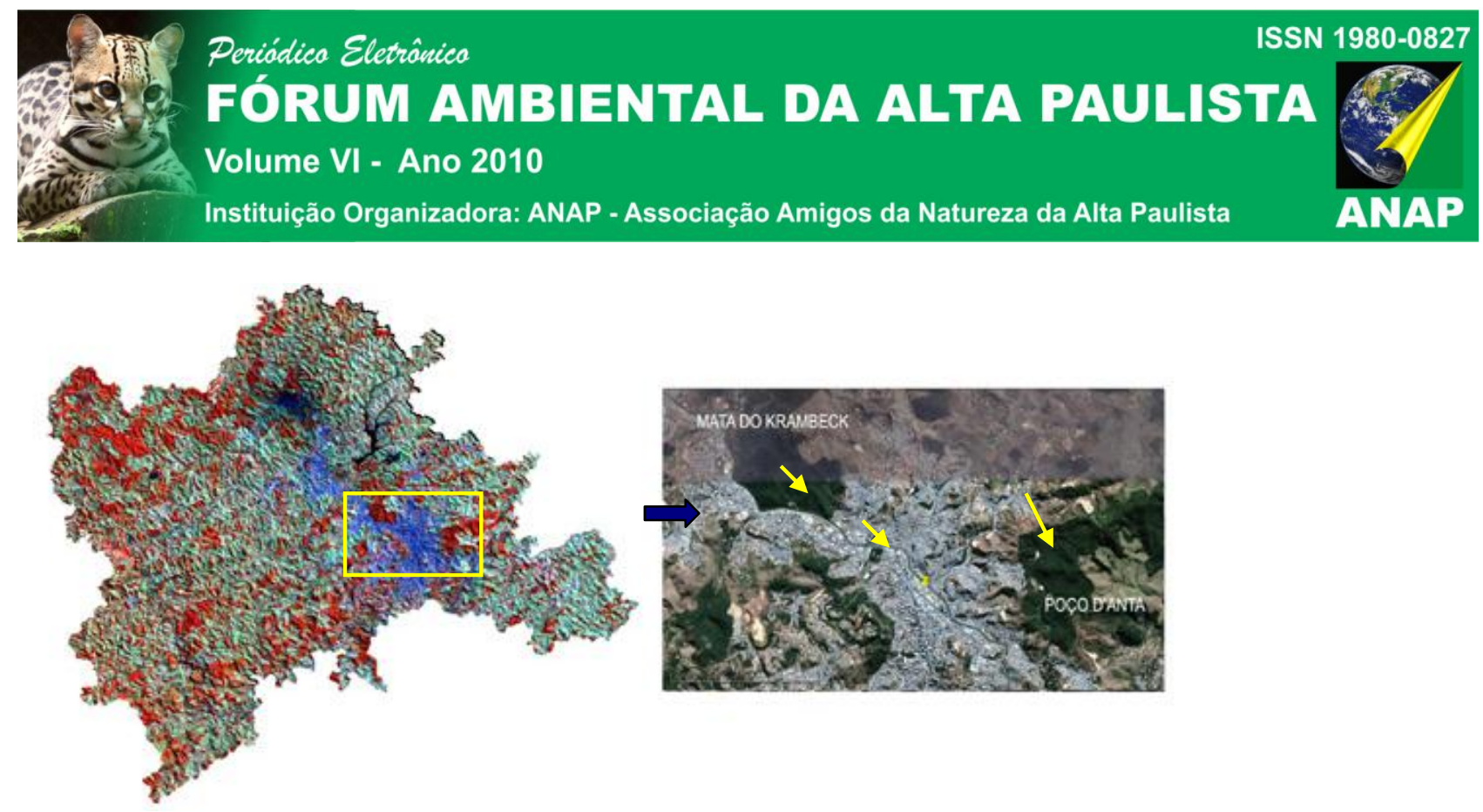

Figura 03: Classe Solo Urbano ou Construído e Florestas na composição colorida das bandas R (TM4) G (TM5) B (TM3) e na imagem do satélite NOOA disponível no Google Eart. Fonte: Imagem de Satélite Landsat - 5 - Google Earth, 2009.

\section{TERRA ESTÉRIL OU SOLO EXPOSTO E PASTAGEM(Fig.04):}

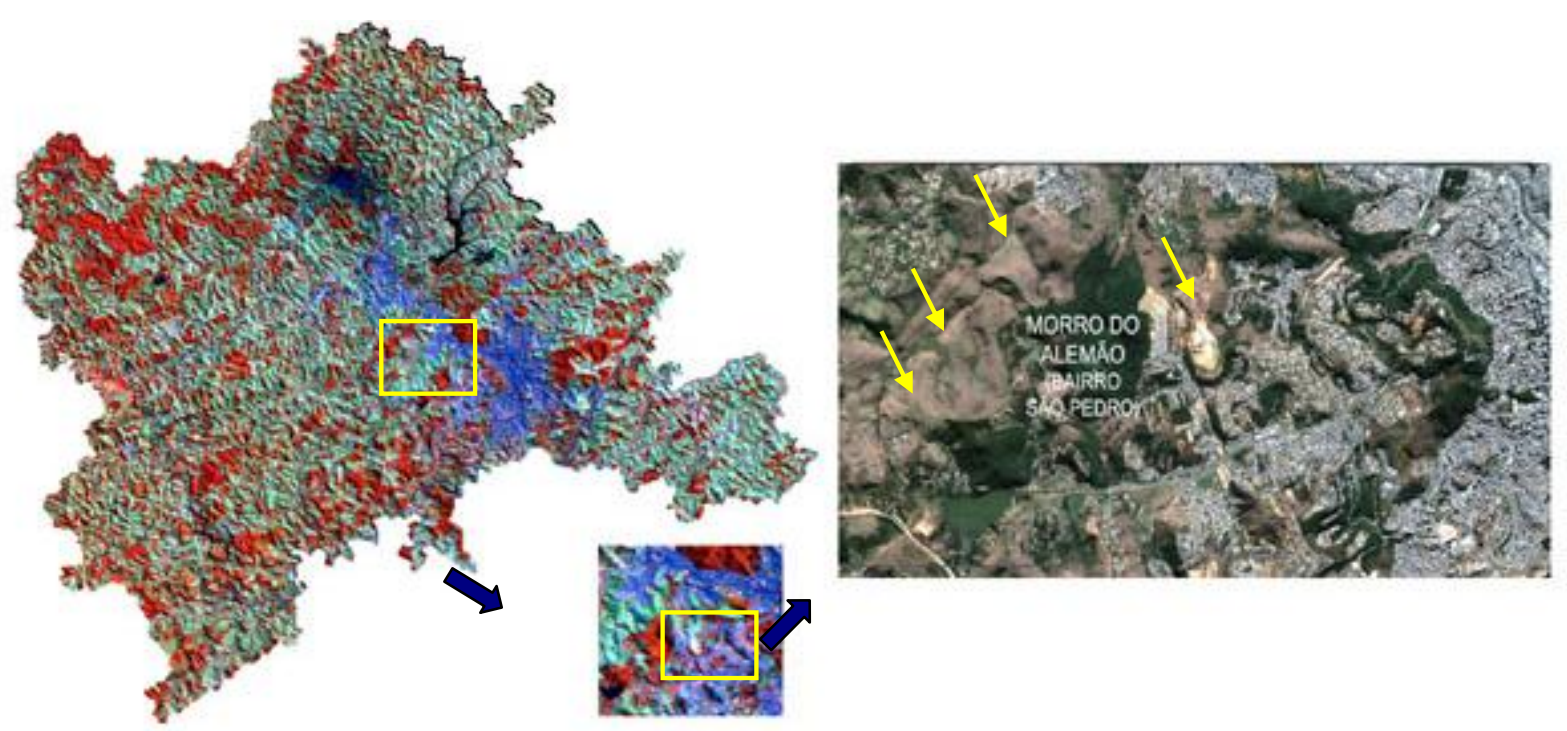

Figura 04: Classe Terra Estéril e Pastagem na composição colorida das bandas R (TM4) G (TM5) B (TM3) e na imagem do satélite NOOA disponível no Google Eart. Fonte: Imagem de Satélite Landsat - 5 - Google Earth, 2009. 

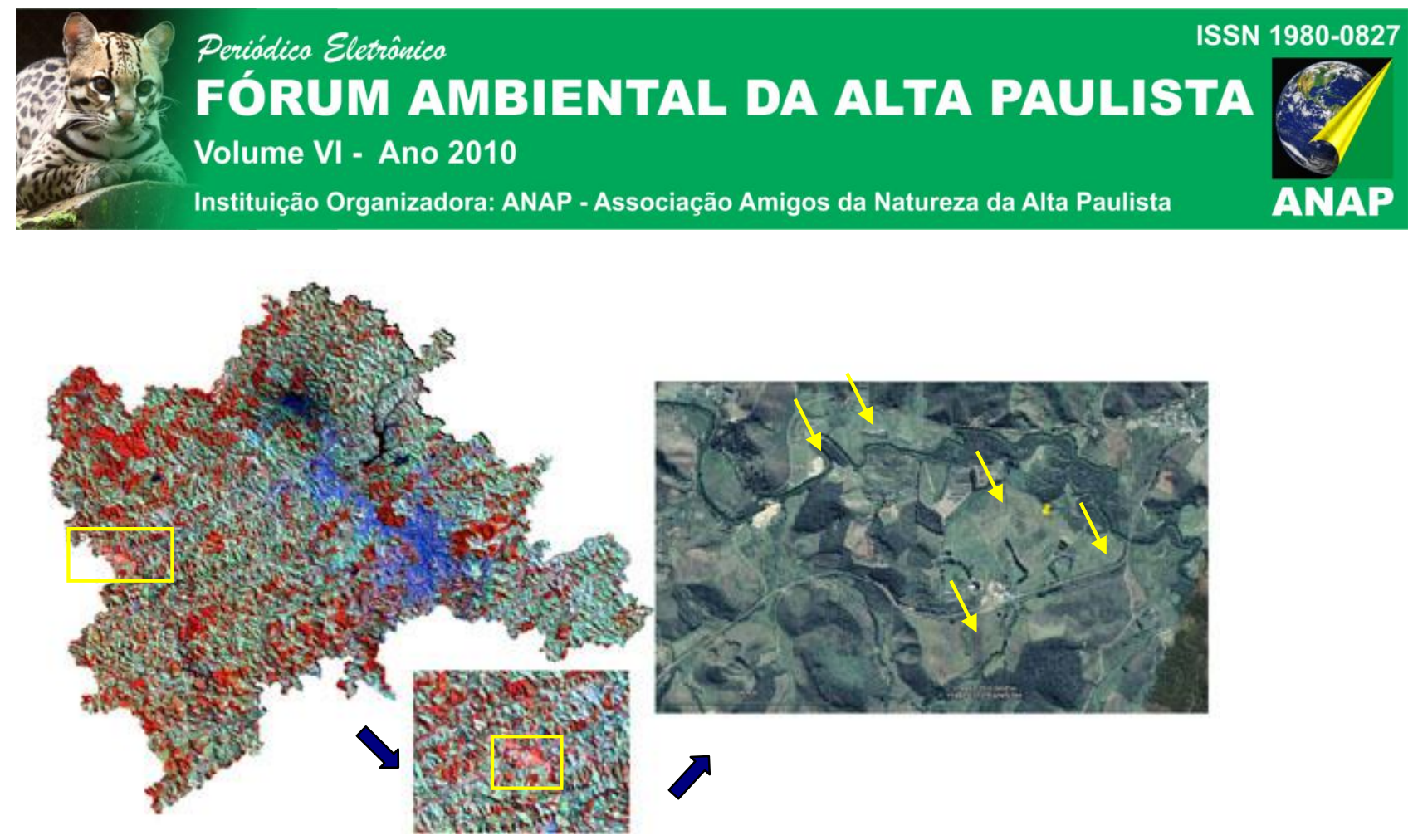

Figura 05: Classe Terra Agrícola na composição colorida das bandas R (TM4) G (TM5) B (TM3) e na imagem do satélite NOOA disponível no Google Eart. Fonte: Imagem de Satélite Landsat - 5 - Google Earth, 2009.

\section{CORPOS D'ÁGUA (Figura 06):}

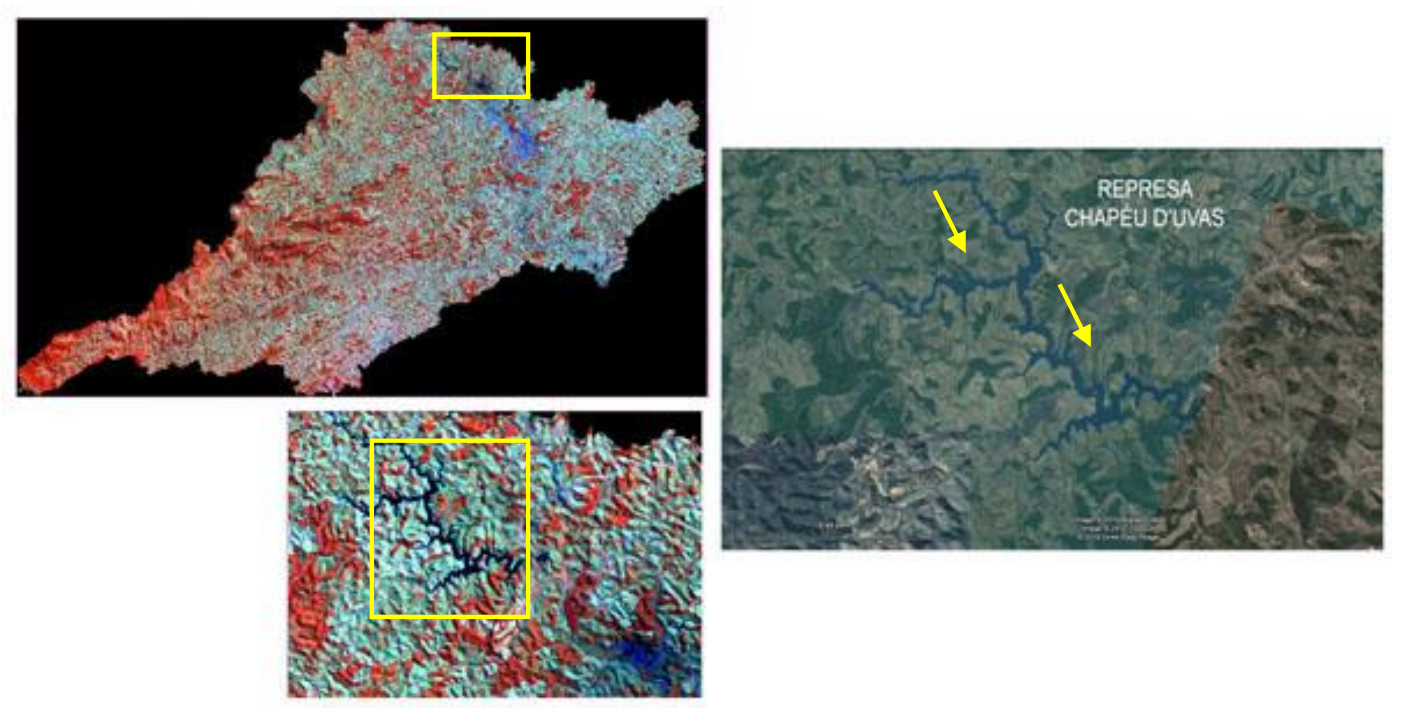

Figura 06: Classe Corpos D'água na composição colorida das bandas R (TM5) G (TM4), B (TM3), com imagem do satélite NOOA disponível no Google Eart. Fonte: Imagem de Satélite Landsat - 5 - Google Earth, 2009. 


\section{FÓRUM AMBIENTAL DA ALTA PAULISTA}

Volume VI - Ano 2010

Os métodos aplicados em conjunto visam extrair as dimensões atuais das classes que compõe a bacia e se mostraram eficazes quanto à escala de trabalho e à extração de informações quantitativas da cena em questão, permitindo análises a respeito da distribuição em valores percentuais das classes na bacia assim como suas contribuições para manutenção da qualidade hídrica e dos demais elementos naturais da mesma.

\subsection{RESULTADOS E DISCUSSÕES}

Através da classificação supervisionada por assinatura de classes foi produzido o seguinte mapa de Uso e Cobertura da Terra da Bacia do Rio Paraibuna baseado em imagens de satélite LANDSAT - 5, data de setembro de 2008 (Figura 07).

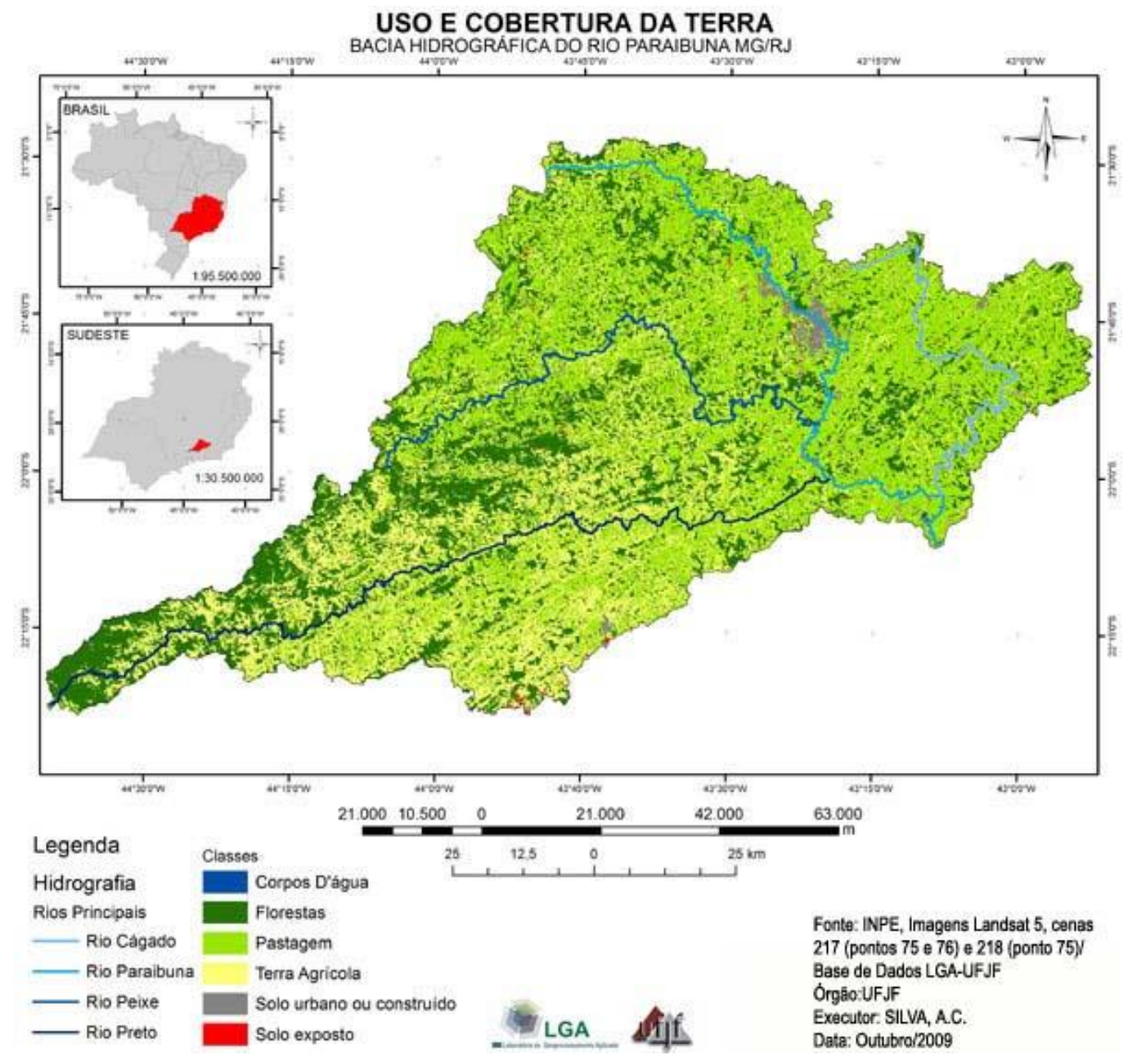


Figura 07: Mapa de Uso e Cobertura da Terra da Bacia do Rio Paraibuna.

Para a análise das condições e distribuição dos elementos de cobertura da terra na bacia faz-se necessário a quantificação de seus valores, os quais foram extraídos da tabela de atributos gerada pela Classificação Supervisionada (Tab. 01).

Tabela de quantificação dos elementos da Cobertura e Uso da Terra da Bacia.

\begin{tabular}{l|l|l|l|l} 
CLASSES & & ÁREA $\left(\mathbf{m}^{2}\right)$ & ÁREA $\left(\mathbf{k m}^{2}\right)$ & ÁREA (\%) \\
\hline Solo Urbano ou Construído & & 117513000 & 117,51 & 1,37 \\
\hline Terra Agrícola & & 233050200 & 2330,50 & 27,11 \\
\hline Pastagem & & 3597307200 & 3597,31 & 41,84 \\
\hline Florestas & & 2429491500 & 2429,49 & 28,26 \\
\hline Corpos D'água & & 90365500 & 90,37 & 0,95 \\
\hline Terra Estéril e Solo Exposto & & 31813814,17 & 31,81 & 0,37 \\
\hline TOTAL: CLASSES & & 8596,99 & 100,00 \\
\hline TOTAL: BACIA & & & $8.597,00^{*}$ & 100,00
\end{tabular}

* Valor arredondado

Fonte: Área em metros e quilômetros quadrados $\left(\mathrm{km}^{2}\right)$ das classes de uso e cobertura da terra da bacia do rio Paraibuna e em percentual (\%).

Podemos notar que a área da bacia é coberta em sua maioria por Pastagens, recobrindo 41,84\%, Áreas Florestadas representando 28,26\%, Terras Agrícolas com 27,11\%, Solo Urbano com 1,37\%, Corpos d'Água e Terra Estéril com 1,05\% e 0,37\%, respectivamente.

Na área da Bacia do Rio Paraibuna, as pastagens, caracterizando-se como área de vegetação herbacea compõem 0 antropismo de maior extensão. São formadas principalmente pelo plantio de gramíneas-forrageiras, comumente mantidas por queima periódica. Os campos formados por capim-gordura sob clima estacional e mantidos pelo fogo anual estão degradados e caminhando para a "savanização". A alternância do período seco prolongado com chuvas intensas acelera o processo de lixiviação e perda das características do solo. A maior parte destas áreas teve sua vegetação original retirada para agricultura no período colonial e correspondem hoje em áreas de vegetação secundária baixa, herbácea, utilizadas eventualmente para fins sem uso específico, atualmente recebe a pecuária enquanto principal atividade econômica rural da região. No município de Juiz de Fora configura como recobrimento do solo de loteamentos abertos e 
não propriamente implantados nas periferias de sua área urbana. É, sobretudo, uma forma de degradação da cobertura vegetal e as regenerações das mesmas só seriam positivas através do replantio de espécies adaptadas ao ambiente.

As áreas florestadas se concentram na porção centro-oeste e sudoeste da Bacia e se mantêm preservada devido o relevo fortemente ondulado nesta região. A resposta espectral se deu num tom de vermelho intenso nas áreas de floresta sendo possível também observar alguma textura oriunda da ocorrência de sombras nas camadas mais superiores dos dosséis. Segundo Ponzoni Shimabukuro (2007), quanto mais rugosa esta textura, maior será a estratificação vertical apresentada pelo dossel, caracterizando extratos pertencentes ao Bioma da Mata Atlântica na região como representado na Figura 11. Para Valverde (1958) o manto escuro das florestas foi substituído pelo pasto claro e aveludado de capim-gordura. Ao longo dos anos os fragmentos de matas continuam a ocupar de forma representativa as áreas citadas. Embora fragmentadas, estas regiões são de suma importância para conservação dos recursos hídricos uma vez que garantem aos mananciais águas de melhor qualidade, menos sedimento e menor quantidade de poluentes. Além disso, evita os processos erosivos do solo e o carreamento de sedimentos para corpos hídricos; atribuem resistência às margens à erosão e conserva a genética das espécies nativas; é sustentáculo à fauna terrestre e aquática, forma paisagem, controla endemias entre outros atributos.

As áreas agrícolas representam a terceira classe de maior representatividade na Bacia do Rio Paraibuna representando problemas bem maiores quanto ao aumento do escoamento superficial. Esta classe identificada muitas vezes por possuir padrões geométricos e colorações num tom de vermelho claro teve mais representatividade na porção centro-sul da bacia e ao longo de cursos d'água. De acordo com Gomes (1986), no setor agrícola, a presença de grande número de pequenos agricultores na zona da mata e conseqüentemente na bacia do rio Paraibuna justifica-se por ser a região de relevo bastante acidentado, limitando a disponibilidade de áreas próprias para a agricultura.

De acordo com Botelho e Silva, 2007, nas áreas agrícolas alguns fatores como exposição do solo às gotas de chuva, ausência da cobertura vegetal durante uma parte do ano e falta de práticas conservacionistas propiciam a formação de fluxo superficial. 
Esta prática, não feita de forma correta com a implantação, estudos e acompanhamentos técnicos específicos, está diretamente relacionada com grande parte dos problemas relacionados à erosão, assoreamento, volume e qualidade da água nas bacias hidrográficas.

$\mathrm{Na}$ classe solos urbanos ou construídos, o município de Juiz de Fora se destaca como a área urbana de maior expressividade, como se pode ver no mapa de Uso e Cobertura e na Figura 10, apresentada anteriormente. O sistema hidrológico nestas áreas urbanizadas apresenta especificidades em relação às áreas de formação vegetais naturais ou cultivadas. Dentre as modificações geradas, a impermeabilização do terreno merece destaque trazendo à cidade preocupações quanto às enchentes, dependendo entre vários fatores, da intensidade e duração das precipitações (Vitte e Guerra, 2007). Podemos observar que no perímetro da área urbana concentram-se as ocorrências de solo exposto que ficam vulneráveis aos processos de erosão superficial devido os fluxos de água que percorrem estas áreas não pavimentadas e desprovidas de vegetação.

Quanto aos corpos d'água, estes foram identificados com maior representatividade nas imagens de satélite e na classificação quando em Represas, lagos, açudes.

\section{CONCLUSÕES}

Podemos concluir que a classificação supervisionada por assinatura espectral se mostrou eficaz ao permitir a investigação de padrões de cobertura e uso da terra, e na coleta de amostras das classes homogêneas se baseando em conhecimento prévio da área da bacia, mesmo que de forma genérica, mas que condiz com a realidade que se quer observar ou representar permitindo a extração de informações quantitativas para análises qualitativas dos elementos de Uso e Cobertura da Terra na Bacia do Rio Paraibuna. Com sua utilização foi possível produzir um mapa que representasse o perfil atual da cobertura da terra numa escala de 1:250.000 com um número de classes satisfatório passível de análises gerais, uma vez que não se tenha trabalhado com uma escala em nível de detalhamento. 
Foi possível concluir que a Bacia apresenta três classes com áreas em valor percentual significativo: pastagens, florestas e terra agrícola, tornando possível traçar o perfil da Cobertura da Terra da Bacia do Rio Paraibuna. Esta informação confirma a atividade pecuária enquanto principal atividade econômica rural da região atualmente e representa, sobretudo, uma forma de degradação da cobertura vegetal na área de estudo. O percentual das áreas de florestas se mostrou bastante fragmentado concentrando-se principalmente na porção central e sudoeste da bacia. As áreas agrícolas se concentram ao longo do Rio Preto e as áreas urbanas ao longo do Rio Paraibuna. Atribuindo a esse, o papel histórico nos processos de ocupação da Zona da Mata Mineira.

Destaca-se bacia na Bacia, um percentual de áreas urbanas pouco significativas, em contrapartida, é no uso intensivo do solo com atividades agrícolas e pastoris que devemos voltar nossa atenção, já que configuram quase $69 \%$ da área. Estas atividades sem meios para orientar o manejo adequado das terras e sem políticas de planejamento e desenvolvimento econômico podem comprometer significativamente os recursos hídricos e a qualidade dos solos da região.

Espera-se que os resultados obtidos tenham contribuído para 0 melhor conhecimento dos elementos e de suas proporções ao longo da Bacia do Rio Paraibuna, sendo fundamental este reconhecimento como subsídios a análises futuras capazes de atender a necessidades governamentais, institucionais ou de estudiosos do tema, no suporte do planejamento, análise ou monitoramento ambiental.

\section{REFERENCIAL}


ARAÚJO, João Paulo de Carvalho. Utilização de métodos e critérios para determinação de rio principal em bacias hidrográficas - o caso do Rio Paraibuna. Juiz de Fora, UFJF 2009. 170p. (Monografia de Conclusão de Curso de Geografia)

DREW, D. Processos interativos homem - meio ambiente. São Paulo: DIFEL, 1986.

FEAM - Fundação Estadual do Meio Ambiente. Bacia do Paraibuna: enquadramento das águas. Belo Horizonte: FEAM-MG, 1996.44 p. (Relatório Técnico).

- Fundação Estadual do Meio Ambiente. Qualidade das Águas Superficiais do Estado de Minas Gerais - Projeto Águas de Minas. Monitoramento das Águas Superficiais de Minas Gerais. Belo Horizonte - FEAM / IGAM, 2000.

GUERRA, A. J. T; CUNHA, S. B. (orgs.). Geomorfologia e Meio Ambiente. - 6ª ed. Rio de Janeiro: Bertrand Brasil, 2006.

IBGE - Instituto Brasileiro de Geografia e Estatística, Manual Técnico da Vegetação Brasileira/ Fundação Instituto Brasileiro de Geografia e Estatística. Rio de Janeiro, Departamento de Recursos Naturais e Estudos Ambientais, 1991.

. -, Recursos Naturais e Meio Ambiente. Uma visão do Brasil, Rio de Janeiro, . -, Departamento de Recursos Naturais e Estudos Ambientais, 1993.

JENSEN, John R., 1949-Sensoriamento remoto do ambiente : uma perspectiva em recursos terrestre / John $R$, Jensen; tradução José Carlos Neves Epiphanio (coordenador) et al. São José dos Campos, SP: Parêntese, 2009.

LAMAS, Fernando Gaudereto; SARAIVA, Luiz Fernando; ALMICO, Rita de Cássia da Silva. A Zona da Mata Mineira: Subsídios para uma historiografia. Artigo. Anais do V

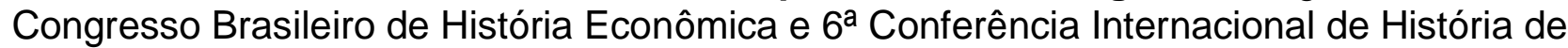
Empresas, 2003. Disponível em < http://ideas.repec.org/s/abp/he2003.html $>$. Consultado em 29 de maio de 2010.

MOREIRA M. A.. Fundamentos do Sensoriamento Remoto e Metodologias de Aplicação. - 3á. ed. - Editora UFV, 2007.

MOTA, Suetônio. Preservação de Recursos Hídricos. Rio de Janeiro: ABES, 1988.

NASCIMENTO. W. M. \& VILAÇA, M. G. Bacias Hidrográficas: Planejamento e Gerenciamento. Publicado na revista eletrônica da Associação dos Geógrafos Brasileiros, Três Lagoas, n. 7, maio de 2008.

ORLANDO, Paulo Henrique Kingma. Produção do espaço e gestão hídrica na Bacia do Rio Paraibuna (MG-RJ): uma análise crítica / Paulo Henrique Kingma Orlando. Presidente Prudente: [s.n.], 2006. 295 f., il. Tese (doutorado) - Universidade Estadual Paulista, Faculdade de Ciências e Tecnologia. 


\section{Periódica Eletrânica

SCHIAVETTI, A.; CAMARGO, A. F. M. Conceitos de Bacias Hidrográficas: teorias e aplicações. Ilhéus, Ba: Editus, 2002.

VIEIRA, Alice Maria Barreto. Sistema de Classificação de cobertura e uso da terra: uma abordagem em múltiplos níveis/ Alice Maria Barreto Vieira. - Rio de Janeiro: UFRJ/IGEO, 2005. xvi, 205 f., il. Tese (doutorado em Geografia) - Universidade Federal do Rio de Janeiro,

Departamento de Geografia, Instituto de Geociências.

VITTE, A. C., GUERRA, A. J. T. (Orgs.) Reflexões sobre a Geografia Física no Brasil.

2. ed. Rio de Janeiro: Bertrand Brasil, 2007. 